\title{
CHOICE OF PARAMETERS FOR THE ELECTRODRIVE DIAGNOSTIC SYSTEM OF HYBRID VEHICLE TRACTION
}

\author{
S. Arhun ${ }^{1 *}$, Yu. Borodenko ${ }^{1}$, A. Hnatov ${ }^{1}$, A. Popova ${ }^{2 * *}$, H. Hnatova ${ }^{1}$,
} N. Kunicina ${ }^{3 * \star *}$, A. Ziravecka ${ }^{3}$, A. Zabasta ${ }^{3}$, L. Ribickis ${ }^{3}$

${ }^{1}$ Department of Vehicle Electronics, Kharkiv National Automobile and Highway University, Khrakiv, UKRAINE

${ }^{2}$ Department of Accounting, Audit and International Economic Relations, Kharkiv National Automobile and Highway University, Khrakiv, UKRAINE

${ }^{3}$ Riga Technical University, Faculty of Power and Electrical Engineering, Institute of Industrial Electronics and Electrical Engineering, Riga, LATVIA

*e-mail: shasyana@gmail.com*; angelikapopova@meta.ua**;

Nadezda.Kunicina@rtu.Iv***

When operating a hybrid vehicle (HEV), it is important to reduce maintenance and repair costs. The HEV electric drive (ED) consists of electronic, electrical and mechanical parts and is considered a complex diagnostic model. The availability of an electrical part greatly simplifies the process of monitoring and obtaining information about the state of the system. In order to create a hybrid diesel-electric propulsion system (HDEPS), the choice of structural and functional parameters as diagnostic ones is justified, the control points are chosen, and the necessary accuracy and unambiguity of measurements are determined. Qualitative evaluations of the electrical processes occurring in the power supply circuit of ED from a high-voltage accumulator battery for the selection of diagnostic parameters according to the criteria of sensitivity, informative character, stability and manufacturability of measurements are presented. It has been revealed that during HDEPS diagnostics both stable and transient modes of operation of electric machines should be considered; for analysis of ED technical state it is necessary to have information about current mode of HDEPS load; for measurement of instantaneous values of supply voltage and consumption current it is necessary to select the sensors with short response time and linear conversion function. In terms of sensitivity to structural changes in the circuit and parametric deviations, it is necessary to choose, as diagnostic parameters, the voltage or current, depending on the mode of operation of the ED and the point of measurement of the electrical value. The obtained results are the basis for creating a new system of diagnostics of electric power supply HDEPS in this direction.

Keywords: diagnostics, hybrid electric vehicle, hybrid power plants, simulation model, traction electric drive. 
Deterioration of the environmental situation and a significant reduction in natural resources not only accelerated the development of energy-efficient technologies and alternative sources of electrical energy, but also became the root cause of the popularization of vehicles on electric traction electric vehicles [1], [2]. Electric vehicles can be divided into two types: those that use only electric motors (EM) and those that drive a hybrid electric vehicle and ICE (plug-in hybrid electric vehicle (PHEV), hybrid electric vehicle (HEV)). A few years ago it seemed that hybrid electric vehicles were a temporary option before the total introduction of EM [3]. Several IoT methods are widely used in the vehicle operation, control, diagnostics, as well as for interconnection with other participants of traffic flow [4]-[6]. However, scientists from many countries continue to work on improving hybrid power plants (HPP) [7], improving their technical and operational characteristics [8], [9], [7], [10], [11], and car manufacturers continue to produce them. At present, cars, trucks and buses with HPP are mass-produced by automobile manufacturers of the world (Honda, General Motors, Toyota, Lexus, Ford, Volkswagen), large energy companies and national laboratories (EPRI, General Electric, NREL, INEEL, ISE Research). This is explained by the advantages of hybrid vehicles, namely their ecological and economic efficiency in comparison with cars with internal combustion engines; independence from electric fueling stations in contrast to EM [12], [13], [7].

However, PHEV and HEV have a significant drawback that constrains their production and application - this is a complex design, which increases the likelihood of failure of components and parts of the HPP, and makes it difficult to diagnose and repair them. Therefore, although the technical and economic characteristics of HPP vehicles are improving every year, their production technology is improving and becoming cheaper, and the relevance of problems associated with the maintenance of hybrid concepts is increasing.

When creating the HPP, it is extremely important to choose power and energy elements, the principle of energy accumulation, the basic scheme, the type of thermal engine, its capacity and operating modes. The second aspect of improving hybrids is to reduce operating costs in terms of their maintenance and repair, where the diagnosis of the technical condition of HPP has the dominant part.

Toyota cars (Camry Hybrid, Highlander Hybrid, Prius, Lexus RX - 400h, Lexus GS 450h) and Ford (Escape Hybrid, Mercury Mariner Hybrid) use a mixed layout of HPP, which is based on two electric machines operating in engine and generator modes [15].

The electric (ED) hybrid drive consists of electronic (control and power), electric (winding circles of machines and apparatus) and mechanical (transmission) parts and is considered a complex diagnostic model. Malfunctions of such a system can be caused by failure of electronic components, destruction of electrical circuits and wear and tear of mechanical parts. Meanwhile, the presence of an electrical part greatly simplifies the process of monitoring and obtaining information about the state of the system.

When diagnosing ED of general structure, known methods [16]-[18] and approaches are applied: sequential check "from end to beginning"; simulation of 
intermediate signals; opening of feedback circuit; replacement and exclusion of separate elements; vibration method [19], [10], [20].

When checking the control part of EV, it is expedient to use the signature analysis method [20]-[22].

In most cases, the following points define the diagnostic method (technology):

- the purpose of the check (regulatory, emergency);

- the depth of fault location (according to the initial or structural parameters);

- the level of qualification of the operator and diagnostic tools;

- actual state of ED system for the period of diagnostics (presence of signs of malfunction).

In general, the check of the electric part of the ED starts with the control of the voltage levels of all power supplies at idling speed and under the rated load in static modes (without input signals). The control equipment of the drive is checked for adequacy of the output signals under initial conditions without changing the conditions at its inputs. Further localization of faults consists in checking of voltages and signals in control circuit control points (localization up to the level of functional block) and modes of power and signal electronics components (localization up to the level of component). Further, the function of the drive in dynamic modes (start, reverse braking, loading, unloading) is checked. After detection of faulty ED element (unit, apparatus, electric machine) it is diagnosed by structural parameters.

For electric machines, structural diagnostics consists of the following operations: measuring the working gap between the stator and the rotor, the insulation resistance of the armature winding and excitation; checking the connection of the neutral; checking the windings for the absence of closed loops and closing to the body; measuring the force of pressing the brushes of the collector unit; checking the axial and radial backlashes of the rotor shaft [23], [15].

Modern vehicle control systems use onboard self-diagnostic systems based on expert programs integrated into the basic control algorithms. Diagnostic information in such systems is read from the on-board computer by means of diagnostic scanners in the form of error codes, current values of mode parameters, reference values of parameters from the data library [15]. The self-diagnostic system is able to control the technical condition of the control system elements (peripheral devices), which are directly connected to the electronic control block (ECB), but does not allow controlling the actuators, which have galvanic isolation from the ECB, and observing the object of mechatronic system control.

To monitor the technical condition of rotating units of the vehicle (ICE, electric motors, pneumatic engines, components and units of the transmission) during maintenance, it is necessary to use methods in which the information about the state of the object of diagnosis is obtained on the basis of harmonic analysis (vibro-acoustics, analysis of the rotation irregularities of the shaft) [10], [24]-[27]. Due to a high level of modern measuring technology, the designated methods can also be used for the current monitoring of the state of the vehicle power units in transport mode.

The aim of the research is to study the electric drive in order to create a system of diagnostics of hybrid power plant of the car with the justification of the choice of its structural and functional parameters. 


\section{BACKGROUND OF THE STUDY AND SETTING THE TASK OF DIAGNOSTICS OF ELECTRIC VEHICLE OF HPP}

Power circuits of hybrid car ED contain reactive elements and they are switching processes. As a result, power supply circuits are subject to transient processes, the nature of which can be used to determine the technical condition of the power plant. Frequency of transients in ED power supply circuits creates preconditions for harmonic analysis of functions of voltage and current change for the purpose of damaged element localization or electronic circuit installation, as well as electromechanical part of ED. Constant voltage converters, inverters, rectifiers should be referred to the electronic devices that make up the power part of the drive. In the mechanical part of the transmission, mechanical torque converters are used.

Presence of reactive components (capacitors, battery, winding of electric machines and inductive reactors) in the ED scheme, on the one hand, cause slowing down of transients (inertial links), on the other hand, increase the dynamics of changes in electrical signals (differential links), depending on the modes of electrical circuit, the nature of load and circuit connection of reactive components.

At present, the electric drive systems of HPP provide sensors of integral parameters (temperature, average or effective values of electrical signals), characterising the general condition of its power elements. Signals of such sensors inform the control system about the regime state of the electric drive elements in order to optimize the power redistribution between the drive units of HPP. At the same time, the obtained information does not allow identifying the technical state of ED elements and localizing the malfunction. To solve this problem, it is necessary to have a system of monitoring of diagnostic parameters. On the basis of its analysis, it is possible to localize the malfunction, ensure accident-free operation, anticipate the emergency state of the HPP and predict its residual lifetime.

Thus, in order to create a system of diagnostics of the HPP electric drive it is necessary to justify the choice of structural and functional parameters as diagnostic ones, to choose the points of their control, to determine the necessary accuracy and unambiguity of measurements.

As alternative diagnostic parameters, the average and instantaneous values of voltage and currents at the outputs of ED functional blocks are considered during the operation of the HPP according to various schemes of power element power distribution and in all operational modes of HPP load.

At the first stage of the research, the task is to give a qualitative assessment of the electrical processes occurring in the power supply circuit of ED from a high-voltage battery (HVB) in order to select diagnostic parameters according to the criteria of sensitivity, informative character, stability and manufacturability of measurement [15], [28].

\section{ANALYSIS OF THE STRUCTURE OF THE DIAGNOSIS SUBJECT}

Let us consider the typical functional structure of the hybrid car electric drive with the use of the GM valve machine, which is able to work in the modes of engine 
" $\mathrm{M}$ " and generator " $\mathrm{G}$ " and for the control actions absorbs the positions of the accelerator pedal $\alpha$ and the rotation of the machine shaft $\mathrm{n}$ (Fig. 1). On the scheme, thick solid arrows indicate the direction of power transfer in mode "M", thick dotted - in mode "G". Thin arrows symbolise the control signals, while three-dimensional arrows symbolise information signals. The controller of electric machines (KEM) transmits to HVC the data on the current at the output of the inverter and its temperature. The KEM receives data for controlling the $\mathrm{MG}$ machine from the HVC. The output voltages of the converters are regulated by the corresponding signals $f_{1}$ and $f_{2}$. The output power of the inverter and, correspondently, of the electric motor, is guided by the signal $\mathrm{f}_{3}$ and the switching signals $\mathrm{fn}$, which are formed on the basis of the rotor angle signal of the machine $\omega$. The HVC monitors the charging level of the HVB $\mathrm{I}_{3} \mathrm{U}_{\mathrm{ch}}$, its temperature then. HVC also receives information about the temperature of the electrical power devices and the value of the electrical load of the HVB [12].

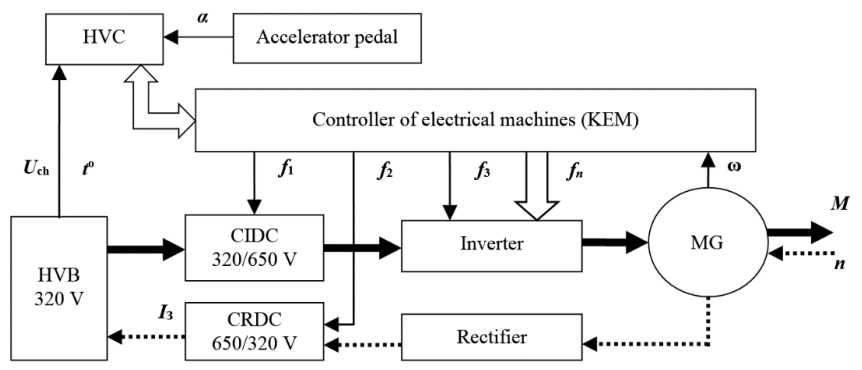

Fig. 1. Scheme of functional electric drive: HVC - a high voltage controller; HVB - a high voltage battery; CIDC - a converter that increases DC voltage; CRDC - a converter that reduces DC voltage.

The level and the value of the pulse pressure on the vortex of the CIDC is the same as the value of the navantagenna (electric motor and inverter mill). Inconsistencies in the electrical field phase will be the victimization of the periodic program function, and in the case of the mechanical transmission - the victimization of the HVB.

\section{APPROBATION RESULTS OF THE SIMULATION MODEL}

To simulate the processes in the circles of the valve motor system, an imitation model of its circuitry in the application package "Matlab/Simulink" was built (Fig. 2).

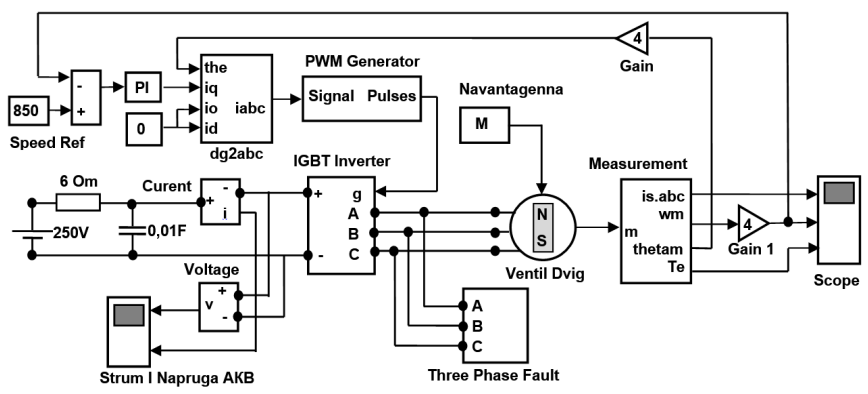

Fig. 2. Simulation model of a valve motor system. 
The model contains a three-phase magnetoelectric synchronous machine (Ventil Dvigatel) controlled by a three-phase inverter (IGBT Inverter), inverter control unit (PWM Generator) and coordinate converter dq2abc.

The speed of the drive is set by the Speed Ref unit. The measurement of the machine variable state is carried out by the measurement unit, and the analysis of the instantaneous values of the electrical parameters of the power supply circuit is carried out by the Strum i Napruga AKB oscilloscope.

The model does not take into account the influence of distributed installation parameters of the device, and examines only the modes of electric drive and considers the scheme without a pulse converter of direct voltage CIDC.

Figure 3 represents the time diagrams: phase current $i_{p}$, rotor speed $n$ and torque on the shaft $\mathrm{M}$ of the valve motor; current $\mathrm{i}_{\mathrm{B}}$ and voltage $\mathrm{u}_{\mathrm{B}}$ in the power supply circuit of the inverter (high-voltage battery).

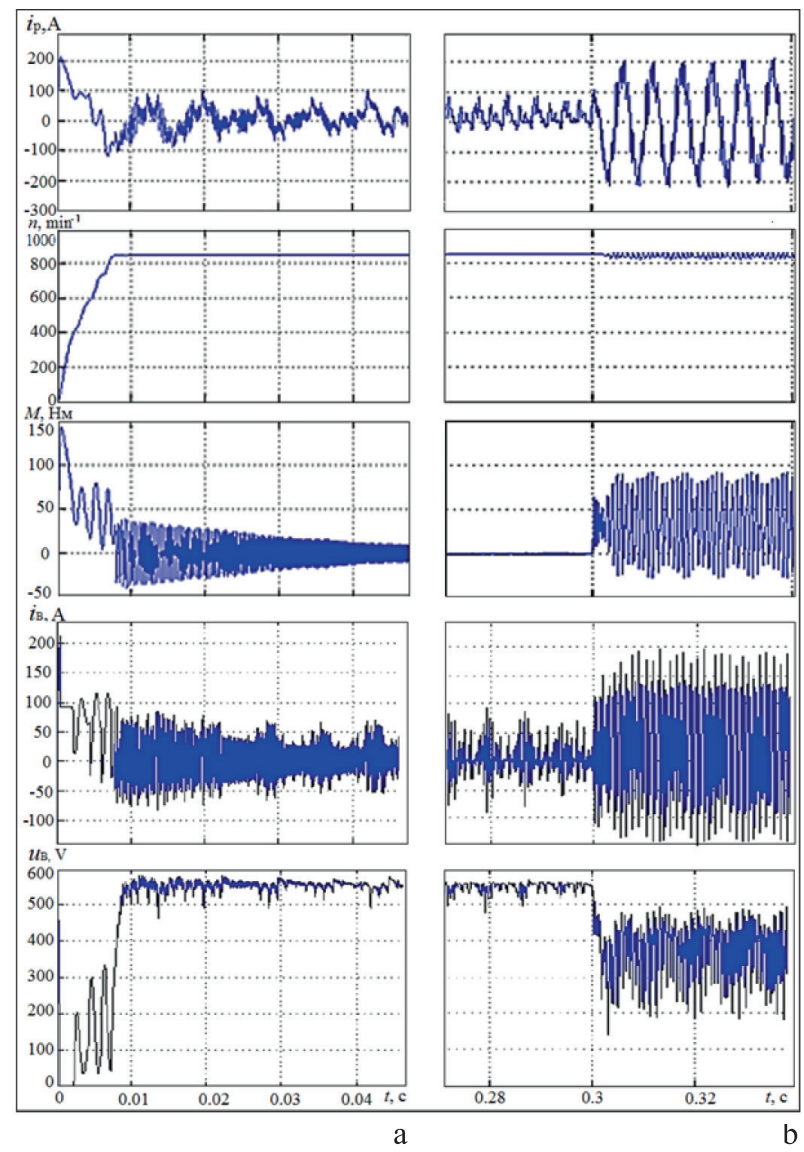

Fig. 3. Time diagrams of electromechanical processes of a drive with the valve electric motor: $\mathrm{a}-\mathrm{at}$ acceleration without loading; $b$ - at connection of loading.

The analysis of the oscillogram (Fig. 3) shows that both stable and transient modes of operation of electric machines should be considered when diagnosing the actuator.

Fragmentally combined diagrams give an idea of the complexity of transients in the circuits of the valve motor system in different modes of operation of a functional electric drive system. It is obvious that at occurrence of malfunctions in system, character of transients will change.

System malfunctions that do not cause 
the drive to shut down, but degrade its performance, include

- loss of HVB capacity and filter capacitor;

- the inverter key exit saturation mode;

- $\quad$ punching of individual keys;
- increased transient resistance at the mounting connections;

- interturn faults in traction motor windings;

- breakdown of power supply circuits on the body and other.

\section{CONCLUSIONS}

When operating a hybrid vehicle, it is important to reduce maintenance and repair costs. The HEV electric drive (ED) consists of electronic (control and power), electric (winding circles of machines and apparatus) and mechanical (transmission) parts and is considered a complex diagnostic model. The presence of an electrical part greatly simplifies the process of monitoring and obtaining information about the state of the system.

To create the HDEPS diagnostic system, the choice of structural and functional parameters as diagnostic ones was justified, the points of their control were chosen, and the necessary accuracy and unambiguity of measurements were determined.

The analysis of oscillograms shows that during diagnostics of the electric drive it is necessary to consider both stable and transient modes of operation of electric machines.

When measuring the diagnostic parameters, it is necessary to have information about the current load mode of the HPP in order to analyse the technical state of the ED.

Functions of current and voltage changes are characterised by harmonics caused by switching of the inverter keys, the frequency of which is hundreds of hertz (Fig. 3). Therefore, sensors with short response times and a linear conversion function should be selected to measure the instantaneous values of supply voltage and consumption current.

In the case of sensitivity to structural changes in the circuit (element faults) and parametric deviations (change of nominal values), it should be chosen as diagnostic, voltage or current parameters, depending on the operation mode of the actuator and the measuring points of the electrical value.

Faults in the electrical and mechanical parts of the actuator cause changes in the current values of signals and the spectral composition of their time functions. Therefore, for structural and parametric identification of the technical state of the HPP it is advisable to apply methods of harmonic analysis.

The obtained results of the research confirm a hypothesis about the possibility of creation of a new system of diagnostics of electric power supply of a traction electric drive of the hybrid car and they serve as a basis for the further studies in this area.

\section{ACKNOWLEDGEMENTS}

The present research has been conducted under the scientific research "Development of the System of Energy Saving and Electric Energy Generation for Vehicles", 0219U100696, funded by the Ministry of Education and Science of Ukraine. 


\section{REFERENCES}

1. Arhun, S., Hnatov, A., Dziubenko, O, \& Ponikarovska, S. (2019). A Device for Converting Kinetic Energy of Press into Electric Power as a Means of Energy Saving. J. Korean Soc. Precis. Eng., 36 (1), 105-110.

2. Pațins, A., Arhun, S., Hnatov, A., Dziubenko, O., \& Ponikarovska, S. (2018). Determination of the Best Load Parameters for Productive Operation of PV Panels of Series FS-100M and FS110P for Sustainable Energy Efficient Road Pavement. In 2018 IEEE 59th International Scientific Conference on Power and Electrical Engineering of Riga Technical University (RTUCON 2018): Conference Proceedings (pp. 1-6), 12-13 November 2018, Riga, Latvia.

3. Mahmoud, M., Garnett, R., Ferguson, M., \& Kanaroglou, P. (2016). Electric Buses: A Review of Alternative Powertrains. Renew. Sustain. Energy Rev., 62, 673-684.

4. Pațins, A., \& Kuniicina, N. (2015). The new approach for passenger counting in public transport systems. In: Proceedings of the 2015 IEEE 8th International Acquisition and Advanced Computing Systems: Technology (pp. 53-57), 24-26 September, 2015. Warsaw: IDAAC 2015. ISBN 978-14673-8359-2.

5. Pațins, A., \& Kuniicina, N. (2014). The Use of remote sensing technology dynamics study and analysis. In: Transport Means 2014: International Conference (pp. 63-66), 23-24 October 2014, Lithuania, Kaunas. ISSN 2351-4604.

6. Pațins, A., \& Kuṇicina, N. (2015). Realtime data collection and easy passenger counting method for public transport system In: Transport Means 2015: Proceedings of the Conference (pp. 329-332), 22-23 October, 2015, Lithuania, Kaunas, ISSN 1822-296X.

7. Dvadnenko, V., Arhun, S., Bogajevskiy, A., \& Ponikarovska, S. (2018). Improvement of economic and Ecological Characteristics of a Car with a Start-Stop System. Int. J. Electr. Hybrid Veh., 10 (3), 209-222.

8. Lanzarotto, D., Marchesoni, M., Passalacqua, M., Prato, A. P., \& Repetto, M. (2018). Overview of Different Hybrid Vehicle Architectures. IFAC-Pap., 51 (9), 218-222.

9. Gunji, D., \& Fujimoto, H. (2013). Efficiency Analysis of Powertrain with Toroidal Continuously Variable Transmission for Electric Vehicles. In: IECON Proceedings (Industrial Electronics Conference), (pp. 6614-6619).

10. Migal, V., Arhun, Shch., Hnatov, A., Dvadnenko, V., \& Ponikarovska, S. (2019). Substantiating the Criteria for Assessing the Quality of Asynchronous Traction Electric Motors in Electric Vehicles and Hybrid Cars. J. Korean Soc. Precis. Eng., 10 (36), 989-999.

11. Xie, S., He, H., \& Peng, J. (2017). An Energy Management Strategy Based on Stochastic Model Predictive Control for Plug-in Hybrid Electric Buses. Appl. Energy, 196, 279-288.

12. Onat, N. C., Kucukvar, M., \& Tatari, O. (2015). Conventional, Hybrid, Plug-in Hybrid or Electric Vehicles? State-Based Comparative Carbon and Energy Footprint Analysis in the United States. Appl. Energy, 150, 36-49.

13. Huang, Y., Surawski, N. C., Organ, B., Zhou, J. L., Tang, O. H., \& Chan, E. F. (2019). Fuel Consumption and Emissions Performance under Real Driving: Comparison between Hybrid and Conventional Vehicles. Sci. Total Environ., 659, 275-282.

14. Ak, N., \& Demirbas, A. (2016). Promising Sources of Energy in the Near Future. Energy Sources Part Recovery Util. Environ. Eff., 38 (12), 1730-1738.

15. Borodenko, Yu. N., \& Cherevach, A. V. (2012). "Kontseptsiia diahnostyky elektropryvoda hibrydnoho avtomobilia," [Hybrid Car Electric Drive Diagnostics Concept]. Automobile Transport, 30. 
16. Apse-Apsīitis, P., Avotiņš, A., \& Ribickis, L. (2014). Different approaches consumption monitoring. In: Proceedings of the 16th Eur Electronics and Applications (pp. 1-5), 26 February 2014, Finland, Lappeenranta. Available at: doi:10.1109/EPE.2014.691

17. Deuse, J., Grenard, S., Karoui, K., Samuelsson, O., Gertm Sauhats, A., Ribickis, L., ... \& Hager, M. (2006). Sollerkvist Dispersed energy resources with power system in Norma. In: The 41st CIGRE Session: Proceedings (pp. 1-12), 22 February 2006, France, Paris. ISBN 9782858730216.

18. Apse-Apsīis, P., Avotiņš, A., \& Ribickis, L. (2013). Self-tuning CoreConverter for Powering Loads on Rotating Shafts. Electron 2013, 19 (2), 41-44. e-ISSN 2029-5731. ISSN 1 doi:10.5755/j01. eee.19.2.3466

19. Malafeev, S. I., \& Novgorodov, A. A. (2016). Design and Implementation of Electric Drives and Control Systems for Mining Excavators. Russ. Electr. Eng., 87 (10), 560-565.

20. Ishkova, I., \& Vítek, O. (2015). Diagnosis of eccentricity and broken rotor bar related faults of induction motor by means of motor current signature analysis. In: 2015 16th International Scientific Conference on Electric Power Engineering (EPE), (pp. 682-686), 20-22 May 2015, Czech Republic.

21. Verucchi, C., Bossio, J., Bossio, G., \& Acosta, G. (2016). Misalignment Detection in Induction Motors with Flexible Coupling by Means of Estimated Torque Analysis and MCSA. Mech. Syst. Signal Process., $80,570-581$.
22. Gan, C., Wu, J., Yang, S., Hu, Y., Cao, W., $\& \mathrm{Si}$, J. (2016). Fault Diagnosis Scheme for Open-Circuit Faults in Switched Reluctance Motor Drives Using Fast Fourier Transform Algorithm with Bus Current Detection. IET Power Electron., 9 (1), 20-30.

23. Chekalin, V. G. (2011). Diagnosis and adjustment of automated electric drives, Uchebnoe posobie dlya VTUZov. Dushanbe: TTU im. M. Osimi.

24. Dąbrowski, Z., \& Dziurdź, J. (2016). Simultaneous Analysis of Noise and Vibration of Machines in Vibroacoustic Diagnostics. Arch. Acoust., 41 (4), 783-789.

25. Boniecki, R., \& Miciak, M. (2018). The Decision Making Process of a State Technical Facilities Based on Rough Set and Vibroacoustic Estimates. MATEC Web of Conferences 2018, 182, 02016.

26. Glowacz, A., \& Glowacz, Z. (2017). Diagnosis of Stator Faults of the SinglePhase Induction Motor Using Acoustic Signals. Appl. Acoust., 117, 20-27.

27. Borodenko, Y., Ribickis, L., Zabasta, A., Arhun, Shch., Kunicina, N., Hnatova, H., ... \& Kunicins, K. Using the Method of the Spectral Analysis in Diagnostics of Electrical Process of Propulsion Systems Power Supply in Electric Car. unpublished.

28. Fedotovs, J., Žiravecka, A., Bunina, I. (2019). Testing of Technical Indicators of Accumulators by Means of Complex Computer Model of EV. Electrical, Control and Communication Engineering, Riga, Latvia - submitted for publication. 